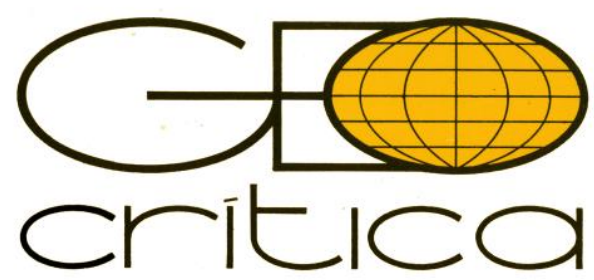

\title{
LA COVID- 19 Y LAS VIEJAS EPIDEMIAS. NO ES LA TERCERA GUERRA MUNDIAL, ES EL CAPITALISMO
}

\author{
Antonio Buj Buj \\ Dr. Geografía Humana (UB) \\ antoniobujbuj@gmail.com
}

\section{La COVID-I 9 y las viejas epidemias. No es la Tercera Guerra Mundial, es el capitalismo (Resumen)}

A finales de 2019 apareció en la ciudad china de Wuhan, provincia de Hubei, un nuevo coronavirus, el SARS-CoV-2, causante de la llamada COVID-19, asociada a problemas respiratorios. El 11 de marzo de 2020, la Organización Mundial de la Salud (OMS) consideró este coronavirus como pandémico, es decir que afectaba a la mayoría de países. A mediados de abril ya se registran más de dos millones de infectados y más de cien mil muertos en todo el mundo. El planeta vive en un estado de alerta general, con confinamientos masivos de la población. Algún dirigente político ha hablado de Tercera Guerra Mundial. A falta de medicamentos y de una vacuna eficaz contra el virus, se hace precisa una evaluación de la pandemia, tanto de las consecuencias como de las causas. Junto a las cuestiones epidemiológicas de la enfermedad, este trabajo se interroga por su geografía, ecología o historia, sin olvidar a muchas otras patologías infectocontagiosas, causantes de millones de muertes al año. La crisis pandémica actual puede generar en el futuro un nuevo marco de relaciones sociales, políticas o económicas a escala planetaria.

Palabras clave: COVID-19, pandemia, viejas epidemias, salud pública, OMS, Tercera Guerra Mundial, capitalismo.

\section{COVID-I 9 and the old epidemics. It's not the Third World War, it's capitalism (Abstract)}

At the end of 2019, a new coronavirus - SARS-CoV-2, the virus strain that causes the Covid-19 disease, which is associated with respiratory problems - appeared in Wuhan, the capital of China's Hubei Province. On March 11, 2020, the World Health Organisation (WHO) declared this coronavirus a pandemic as it spread worldwide. By mid April, more than 2 million infected cases and more than 100,000 deaths had been registered worldwide. The planet is currently living in a state of emergency, with billions confined in their homes. Some political leaders have likened the current situation to a Third World War. Without adequate medicine or treatment, and without a vaccine, it is necessary to evaluate the consequences and the causes of the pandemic. This essay examines epidemic issues of Covid-19, as well as its geography, ecology, and history, and also discusses other contagious pathologies that cause 
millions of deaths per year. The current pandemic crisis could trigger a new framework of social, political, and economic relationships worldwide.

Key words: Covid-19, pandemic, old epidemics, public health, WHO, Third World War, capitalism.

El historiador británico Eric Hobsbawm (1917-2012) tituló sus memorias Interesting Times. A Twentieth-century Life (en castellano, Años interesantes. Una vida en el siglo XX, 2003). En ellas da cuenta de sus ricas experiencias a lo largo de casi todo el siglo XX. Hobsbawm ha sido uno de los mejores notarios, en sentido figurado, de la centuria pasada, un siglo caracterizado por numerosos éxitos, pero también por algunos de los acontecimientos más trágicos de la humanidad. No es cuestión aquí de hacer un recuento de unos y de otros, pero sí apuntar que en cien años la población mundial se ha multiplicado por cuatro, que la mayor parte de la misma vive en ciudades, que la globalización ha llegado a ser planetaria o que el hombre ha modificado de manera irreversible el medio físico de la Tierra. También que la humanidad ha conseguido erradicar la viruela ${ }^{1}$, una de las enfermedades que causaba más estragos en el pasado, que ha creado numerosas vacunas frente a otras enfermedades, pero que siguen persistiendo cientos de enfermedades infectocontagiosas que matan a millones de personas al año. Estas muertes son recurrentes en la mayor parte del mundo menos industrializado, sometido a tensiones de todo tipo derivadas de la carencia de recursos económicos, sanitarios, educativos, habitacionales, o por falta de equidad política y social.

De repente, el mundo occidental se ha despertado con el mayor reto desde la Segunda Guerra Mundial, en palabras de Angela Merkel, la canciller alemana, por culpa de la COVID-19 o enfermedad por coronavirus ${ }^{2}$. En el mismo diario, casi monográfico sobre esta patología generada por el virus SARS-CoV-2, se habla de virus geopolítico, con acusaciones entre las dos grandes potencias, China y Estados Unidos de América, sobre una posible responsabilidad militar en el diseño del mortífero germen. En las páginas siguientes se anuncia que Nueva York baja el telón por culpa del virus, que Portugal decreta el estado de emergencia para intentar blindarse, que Moscú utiliza el coronavirus para sembrar la confusión en Europa, o que el presidente del gobierno español, Pedro Sánchez, plantea para el 2021 los "presupuestos de la reconstrucción" por culpa de los estragos que va a causar el coronavirus. España, continúa el diario, está en estado de alarma, con una cantidad enorme de despidos temporales, muchas de las grandes empresas cerradas, las actividades culturales y deportivas paralizadas, y con las UCI (unidades de cuidados intensivos) de los hospitales al límite. Todo ello con los 14.678 casos confirmados de coronavirus y los 640 muertos provocados por el mismo. La edición digital del mismo diario, un día después nos informa que los casos confirmados en España superan ya los veinte mil y los muertos los mil.

Diez días después, la edición en papel del mismo diario nos apunta que los positivos por coronavirus en España son 72.248, los muertos 5.707, y las altas médicas $12.285^{3}$. Toda la edición es prácticamente monográfica sobre la enfermedad. Resaltamos algunos titulares: "Millones de indios sin trabajo pugnan por volver a sus pueblos", con una fotografía de una aglomeración humana con el pie: Decenas de miles de personas se agolpan a las afueras de Delhi; "Nueva York, otra vez zona cero", rememorando el atentado terrorista en la ciudad del

\footnotetext{
${ }^{1}$ Los expertos han calculado que la viruela acabó con la vida de 300 millones de personas solo en el siglo XX, hasta 1980, año en el que se dio por erradicada <https://www.who.int/csr/disease/smallpox/en/>.

${ }^{2}$ La Vanguardia, 19 de marzo de 2020, p. 6

$<$ http://hemeroteca.lavanguardia.com/edition.html?bd=19\&bm=03\&by=2020>.

${ }^{3}$ La Vanguardia, 29 de marzo de 2020, p. 32-33 <https://www.lavanguardia.com/hemeroteca〉.
} 
11 de setiembre de 2001; "La Covid-19 recalca las carencias de la sanidad en EE.UU."; o, "El último sacrificio del capitalismo", en la que figuras conservadoras, inversores y empresarios multimillonarios animan al presidente Donald Trump a reabrir la economía de ese país cuanto antes. Una de esas figuras, Dick Kovacevich, expresidente de Wells Fargo, se pronuncia en los siguientes términos: "Pongamos a trabajar a los menores de 55 años y veamos qué pasa; unos enfermarán, algunos morirán". Lo único que se puede pensar de individuos así es lo que escribió un genial estadounidense, H. L. Mencken, que en su Prontuario de la estupidez humana dijo que si a algunos individuos les faltaran sus pesados y molestos arreos estarían indefensos ante las moscas y, además, sin cola para espantarlas. El país de Kovacevich, en estos momentos es el que tiene más infectados por coronavirus del mundo, casi 125.000. Como podemos ver, el escenario es extraordinariamente dinámico ${ }^{4}$. El fácil acceso a la información de otros países nos confirma que los problemas relacionados con el coronavirus son globales e igual de dramáticos. La magnífica página web de la Universidad Johns Hopkins de Baltimore ${ }^{5}$ nos permite seguir prácticamente a la hora la marcha de la enfermedad.

Los años interesantes de Hobsbawm tienen visos de convertirse en días, semanas y meses dramáticamente interesantes para toda la humanidad durante 2020. Si se pasa de meses a años será simplemente catastrófico. Para el mundo industrializado porque no está acostumbrado a pandemias como la COVID-19, que en pocos días ha matado ya a miles de personas, ha infectado a cientos de miles y ha empezado a colapsar algunos de los sistemas sanitarios más sólidos del mundo -según la Organización Mundial de la Salud (OMS)- como son los de Italia o España. La incertidumbre ante lo desconocido ha desbocado el desasosiego colectivo. A todo ello, hay que añadir los tiempos de confusión en los que viven los países más ricos, marcados en algunos casos por populismos de derecha, que generan estados de xenofobia, resentimientos contra el diferente o respuestas acientíficas e irracionales a cuestiones técnico-científicas. La Unión Europea tampoco ha sabido dar una respuesta coordinada a la crisis. Cada Estado ha puesto en marcha políticas sanitarias diferentes, aunque parece ser que la inyección financiera europea será cuantiosa. La cuestión principal es saber a quién favorecerá ese dinero. Estados Unidos de América, con decenas de millones de personas sin seguro médico, ha mantenido una posición confusa y errática ante el coronavirus. Los dirigentes del otro gigante americano, Brasil, mantienen a día de hoy políticas demagógicas. Los ejemplos positivos de combate contra la pandemia son los de China, Corea del Sur y Japón, por sus comparativamente limitados casos de la enfermedad, aunque algunos medios de comunicación han puesto en duda los datos oficiales del primero de esos Estados; igualmente, el uso de los teléfonos móviles de los ciudadanos de esos tres países para controlar la pandemia, puede haber causado una clara merma de la libertad individual, por lo menos tal como se conoce en el mundo occidental. Algún autor ha relacionado esta vigilancia digital con futuras formas de control social ${ }^{6}$.

\footnotetext{
${ }^{4}$ Diez días más tarde, la edición en papel de La Vanguardia de 8 de abril ya no hacía el recuento de infectados y muertos. El diario era también monográfico sobre el coronavirus. Una de las noticias destacadas era el anuncio de que la pandemia podía destruir 195 millones de empleos en todo el mundo. La OMS, en su informe de 8 de abril de 2020, registra 1.353.361 infectados y 79.235 muertos por el SARS-CoV-2 en todo el planeta <https://www.who.int/docs/default-source/coronaviruse/situation-reports/20200408-sitrep-79-covid19.pdf?sfvrsn=4796b143_6>.

5 <https://coronavirus.jhu.edu/map.html>.

6 Véanse las reflexiones al respecto del filósofo de origen coreano afincado en Berlín, Byung-Chul Han $<$ https://elpais.com/ideas/2020-03-21/la-emergencia-viral-y-el-mundo-de-manana-byung-chul-han-el-filosofosurcoreano-que-piensa-desde-berlin.html>.
} 


\section{La gran divergencia en la salud pública mundial}

Para los países en vías de desarrollo, con unos sistemas sanitarios muy frágiles, los problemas se multiplicarán dramáticamente. Están en las fases iniciales de la enfermedad. El futuro inmediato será, con seguridad, extremadamente complicado para numerosos colectivos. La esperanza en los países más pobres respecto al SARS-CoV-2 quizás radique en el hecho de que sus poblaciones son jóvenes, en principio el grupo de edad menos vulnerable ante la enfermedad, aunque también es cierto que no disponen de la misma atención alimentaria, habitacional, sanitaria o educacional que en los países más ricos. El trabajo informal generalizado está, en buena medida, en el origen de esas deficiencias, causantes asimismo de los intensos procesos migratorios que se registran en todo el mundo a día de hoy. Habrá que estar atentos también a la incidencia de la pandemia del coronavirus en lo que se conoce como cuarto mundo en los países ricos. Estos se dicen ricos, pero muchos de sus individuos son pobres o muy pobres.

El último ejemplo comparable a la COVID-19, para las generaciones vivas del mundo occidental, es el del VIH, causante del síndrome de inmunodeficiencia adquirida (sida). En la segunda mitad de la década de 1980 tuvo lugar la expansión de este virus a escala planetaria y golpeó también al mundo desarrollado. Uno de los primeros científicos sociales que estudió el problema, el geógrafo Peter Gould, escribía en 1990 que los países ricos habían puesto en marcha programas intensivos de educación sexual para evitar la expansión del virus. El VIH también se transmite por la sangre. El mismo Gould señalaba que en África los mismos hospitales eran focos de infección. Las jeringuillas desechables eran casi desconocidas en amplias zonas o no se tenían medios para la esterilización de las agujas ${ }^{7}$. Los muertos por esta pandemia se han contabilizado en más de 30 millones hasta la fecha, según la $\mathrm{OMS}^{8}$. En el año 2018 los muertos se acercaron a los 770.000, y los infectados a 1,7 millones de personas.

La carga más pesada de las enfermedades infectocontagiosas la padecen los países más pobres. A los muertos ya mencionados anteriormente por el VIH, hay que sumar, según la misma fuente, los fallecidos por tuberculosis en el mismo 2018, un total de 1,5 millones de personas, de las cuales 251.000 estuvieron relacionados con el VIH. Los países más afectados fueron China, India, Pakistán, Filipinas, Indonesia o Sudáfrica. Los muertos por otra de las epidemias más letales, el paludismo, sobrepasaron los 400.000 ese mismo año, y los afectados fueron más de doscientos millones de personas en todo el mundo, con la consiguiente carga para las familias, al no poder los enfermos desarrollar las actividades laborales con normalidad. El mundo rico está libre, en estos momentos, de paludismo. En el mismo sentido, un informe de la Organización de Naciones Unidas para la Alimentación y la Agricultura ${ }^{9}$ denunciaba recientemente que más de ochocientos millones de personas se iban a dormir cada día sin haber ingerido las calorías mínimas para su actividad diaria. El informe es de 2017. La hambruna había aparecido en Sudán del Sur, en Somalia y en el norte de Nigeria. A las guerras, se sumaban las sequías y otros impactos climáticos para explicar las coyunturas, pero en realidad, detrás del hambre está la pobreza y la vulnerabilidad social ${ }^{10}$. En el momento de la redacción de este

\footnotetext{
${ }^{7}$ Gould y Kabel, septiembre de 1990, p. 10 <http://www.ub.edu/geocrit/geo89.htm>.

8 OMS <https://www.who.int/health-topics/hiv-aids/\#tab=tab_1>.

${ }^{9}$ FAO <http://www.fao.org/home/es/>.

${ }^{10}$ El País, 16 de septiembre de 2017, p. 8

<https://elpais.com/elpais/2017/09/05/planeta_futuro/1504624883_402058.html>.

Estos mismos datos, que hablan de 25.000 muertos de hambre al año en todo el planeta, en $<$ https://ourworldindata.org/grapher/malnutrition-death-rates?tab=chart\&time=2017>.
} 
trabajo se han desatado feroces plagas de langosta en el llamado Cuerno de África, que amenazan los recursos agrícolas de millones de personas ${ }^{11}$.

La coyuntura actual ante la COVID-19 es tremendamente compleja en buena parte del planeta, y muy difícil en algunas regiones. Estas varían prácticamente de un día a otro. Sin duda, es el momento de dejar trabajar a los expertos en enfermedades transmisibles, en las diversas escalas: global, regional y local; a los gestores políticos, aconsejados por aquellos; a los ciudadanos, siguiendo las recomendaciones dadas de protección personal y colectiva; y a los científicos, en sus laboratorios en busca de remedios y vacunas contra la patología. Estas son las tareas inexcusables a día de hoy, pero el científico social no debe descuidar el largo plazo. Por ello conviene denunciar la reacción hipócrita del mundo rico ante la nueva pandemia. Siendo la situación muy grave, se ha producido, una vez más, una reacción asimétrica ante un problema epidémico de gran calado como el del SARS-CoV-2. Mientras el problema estuvo en China y otros países vecinos, el mundo occidental no supo o no pudo entender el problema, pero desde que ha golpeado también a los países occidentales, las señales de alarma se han disparado ${ }^{12}$. Todos los medios de comunicación retransmiten casi en directo la marcha de la enfermedad. La cifra total de muertos ya apuntada antes, de $\mathrm{VIH}$, de tuberculosis o de paludismo, apuntalan lo insinuado en este párrafo. Otros virus, causantes de la hepatitis B y $\mathrm{C}$, son los responsables de otro millón de muertes anuales, de manera especial en los países menos desarrollados.

Otro de los argumentos que nos permite hablar de la razón hipócrita del mundo rico es el hecho de que los expertos llevan advirtiendo desde hace mucho tiempo del retorno de las epidemias y de la emergencia y reemergencia de las mismas ${ }^{13}$. En el resumen final de diciembre de 2002 de la revista de la OMS Weekly epidemiological record/Relevé épidémiologique hebdomadaire se exponía que en los últimos meses de aquel año se habían producido brotes de unas cincuenta enfermedades infecciosas ${ }^{14}$. A las que habían vuelto con fuerza como la tuberculosis, el paludismo, la peste, la fiebre amarilla, la lepra o la enfermedad del sueño, había que añadir las llamadas emergentes, relativamente recientes en tiempo histórico, como el ébola, la fiebre hemorrágica de Crimea-Congo o la fiebre del oeste del Nilo. Algunas de estas enfermedades estaban afectando a países como Estados Unidos de América, Australia, Gran Bretaña, Francia, Alemania o España. Por aquellos años, la Organización Mundial de la Salud, incluida en el sistema de Naciones Unidas, estaba sufriendo graves problemas de organización y financiación. Según denunciaba su directora general, Gro Harlem, el presupuesto regular de la organización había disminuido, en términos reales, en un 20 por ciento en los últimos diez años ${ }^{15}$.

Durante las dos últimas décadas, las noticias sobre plagas y epidemias han sido una constante en los medios de comunicación. Nos hemos acostumbrado a conceptos como guerra biológica, contaminación de alimentos, sida, carbunco, fiebre aftosa, peste porcina, legionelosis, síndrome respiratorio agudo y severo (SARS), "gripe del pollo", MERS-CoV, ébola, ahora COVID-19, entre muchos otros, términos que hace algunas décadas o bien eran desconocidos o bien se

\footnotetext{
${ }^{11}$ Buj Buj, 2016.

${ }^{12}$ El amigo José $\mathrm{M}^{\mathrm{a}}$ Echauri me sugiere que seguramente siguen persistiendo las fronteras mentales OrienteOccidente, incluso con prejuicios raciales: a pesar de la globalización, seguimos con el imaginario de El lejano Oriente, y la distancia ideológica en el caso de China.

${ }^{13}$ Véanse, Hagett, 1994; Garrett, 1995; Wilson, 1995; Oldstone, 1998; Buj, 2001

<http://www.scielo.org.mx/pdf/pp/v7n29/v7n29a10.pdf>, 2003

<https://www.raco.cat/index.php/TreballsSCGeografia/article/view/10445/261541>; López Piñero, 2002;

Crawford, 2002; Saluzzo, 2004.

14 <https://www.who.int/docstore/wer/pdf/2002/wer7751.pdf>

${ }^{15}$ Buj, 2001, p. 196.
} 
había dejado de hablar de ellos. En realidad, del "regreso de las epidemias" se empezó a hablar ya en los ambientes especializados en la década de 1980. Esto contrasta con la imagen optimista que desde la ciencia y las organizaciones sanitarias se había dado desde que se declaró erradicada la viruela en 1980, después de una campaña iniciada en 1967 consistente en una vacunación sistemática de la población en los más de treinta países donde la enfermedad seguía siendo endémica. El premio Nobel de medicina de 1960, Sir Mcfarlane Burnet, y el microbiólogo David O. White, escribieron que los países civilizados habían eliminado ya las enfermedades pestilenciales, la peste misma, el cólera, el tifus, la viruela, el paludismo y la fiebre amarilla o que la disentería infantil, la escarlatina y la difteria, en el origen de la mayor parte de la mortalidad infantil, eran ya raras y, en general, extremadamente benignas. A ese aparente triunfo habrían contribuido tanto las medidas de higiene personal como la separación entre los hombres y los transmisores de las infecciones, y especialmente el descubrimiento de los antibióticos y el desarrollo de las vacunas. No obstante, Burnet advertía, de manera premonitoria, que las grandes plagas, "en el supuesto de que la civilización se viniera abajo" y no se pudiera mantener el entramado de la sanidad pública, no tardarían en volver ${ }^{16}$.

Hasta el presente, ni el sida, ni el ébola, ni el SARS, las enfermedades infectocontagiosas que han tenido más trascendencia mediática en las últimas décadas, aunque no las más mortíferas, han conseguido que la civilización se viniera abajo, como tampoco lo conseguirá el SARSCoV-2. Del sida ya hemos apuntado algunos datos. El virus del ébola estuvo confinado a los países del África tropical hasta los inicios del siglo XXI. La enfermedad fue identificada en 1976 en la región de Yambuku, en la República Democrática del Congo. Entre ese año y 1979 aparecieron brotes epidémicos de esta patología en el sur de Sudán. Ya en 1994, el virus apareció de nuevo en Congo, en la ciudad de Kikwit. Según la OMS, hasta junio de ese año se habían infectado 315 personas, de las que 244 fallecieron a causa de hemorragias internas y externas. El número de defunciones alcanzó el 77 por ciento. En los años siguientes hubo muertos por la enfermedad en Gabón, Suráfrica, Congo o Uganda. El peor episodio de ébola tuvo lugar en el período 2014-2016. Los diarios occidentales se llenaron de noticias de la patología. En España hubo dos muertes de casos importados. La página web de la OMS a día de hoy contabiliza un total de 28.616 casos por ébola, con 11.310 muertos, la mayoría en Liberia, Guinea y Sierra Leona. Las razones por las que la enfermedad se extendió en estos países tienen mucho que ver con sus indicadores sociales. Sus índices de desarrollo humano (IDH) estaban en las posiciones 175,179 y 183 de un total de 187 países ${ }^{17}$. Liberia y Sierra Leona habían sido, además, asoladas por la guerra, con gran parte de la población desnutrida y los sistemas de salud devastados. En Congo, el ébola sigue activo. Desde agosto de 2018 hasta marzo de 2020, según la OMS, ha habido 3.453 casos, con 2.264 muertes $^{18}$.

La otra patología mencionada, el síndrome respiratorio agudo y severo (SARS en inglés) puso en jaque a las organizaciones sanitarias internacionales de salud en los inicios de este siglo. En abril de 2003 se tuvo conocimiento de la enfermedad. Este coronavirus había aparecido en la región china de Guangdong a finales de 2002. La hipótesis más plausible sobre su origen es que había dado el salto biológico desde algún animal de consumo al hombre. En los inicios de 2004 se sacrificaron, según la prensa, unas diez mil civetas, una delicia culinaria en el sur de China, supuesto animal transmisor de esta neumonía atípica. La patología se mundializó y una treintena

\footnotetext{
${ }^{16}$ Burnet y White, 1982, p. 12.

${ }^{17}$ El País, 1 de septiembre de 2014, p. 30

<https://elpais.com/sociedad/2014/08/27/actualidad/1409131671_792505.html >.

18 <https://www.who.int/health-topics/ebola\#tab=tab_1> Un análisis del papel de la Geografía frente al ébola, a fin de ayudar a conocer su impacto en futuras crisis, en Viana, Enrique et. al., 1 de noviembre de 2019 <http://www.ub.edu/geocrit/aracne/aracne-236.pdf >.
} 
de países se vieron afectados. La OMS llegó a aconsejar no viajar a varios de esos países. En los meses siguientes, los diarios recogieron regularmente noticias sobre la enfermedad. Hacia mediados de 2003, la OMS anunciaba que esta forma de neumonía había tocado techo. El balance por aquellas fechas era de ochocientas personas muertas y más de ocho mil infectados. Desde 2004 no ha habido nuevos casos, aunque en los meses de abril y mayo de ese año hubo sospechas de algún brote en China, abortados con cuarentenas estrictas ${ }^{19}$.

Coincidiendo con la epidemia de SARS, en 2003 apareció primero en China, y después en otros países asiáticos, lo que se conoció como la "gripe del pollo", patología cercana a la gripe humana provocada por el virus de la cepa A (H5N1). En realidad, según la OMS, ya había habido antes, en 1997, un episodio del mismo patógeno en Hong Kong. La alarma mundial se produjo cuando la enfermedad se fue extendiendo por todo el mundo, de manera especial en África y Europa. Aunque este virus mató a pocas personas, sí causó la muerte de millones de animales y además tuvieron que ser sacrificados docenas de millones de aves más, no solo pollos. Solo en Vietnam, país con diez personas muertas en los inicios de 2004 por la gripe aviar, habían muerto y sacrificado 2,9 millones de $\operatorname{pollos}^{20}$. El problema se arrastró a lo largo de todo 2005. El país más afectado ese año fue China que reconoció una docena de brotes y la muerte de alguna persona. También hubo muertes de personas en Turquía. En los inicios de 2006, la gripe aviar irrumpió en Nigeria. En total, en todo el mundo murieron un centenar largo de personas.

Pocos años después, en abril de 2009 se detectó un brote de gripe en una granja de cerdos en México. Se la denominó gripe porcina, aunque pronto se supo que la causaba una cepa de virus de gripe A (H1N1) con material genético de virus de gripe humana, gripe aviaria y gripe porcina. El 11 de junio de ese año, la OMS la clasificó como pandemia en curso, es decir que iba a afectar a muchos países. Esa declaración originó algunas críticas, pues se consideró que generaba un nivel de alarma desproporcionado ${ }^{21}$. El 10 de agosto de 2010 la OMS anunció el fin de la pandemia, y según esta organización dejó 18.500 víctimas mortales. Estudios posteriores elevaron esa cantidad de manera sustantiva. Toda la comunidad científica concluyó que los más afectados habían sido los menores de 65 años. Muchos países adquirieron millones de dosis de vacunas desarrolladas por laboratorios farmacéuticos privados que no se utilizaron y acabaron caducadas $^{22}$. En los inicios de 2013, se produjeron infecciones en China de otra gripe aviar, en este caso de la cepa A (H7N9). Se registró la muerte de más de seiscientas personas. En paralelo a esta nueva forma de gripe aviar se produjo una epidemia de otro coronavirus, bautizado con el nombre MERS-CoV. Desde setiembre de 2012, hasta día de hoy, a la OMS se le han notificado 2.494 casos en personas, con 858 muertes y 27 países implicados. El reservorio biológico de este patógeno son los camellos. Los primeros casos se registraron en Arabia Saudín ${ }^{23}$.

Vayamos a más datos empíricos sobre el SARS-CoV-2, los que motivan el presente trabajo. A mediados de enero empezaron a salir noticias en los medios de comunicación de la aparición

\footnotetext{
19 <https://www.who.int/csr/resources/publications/SARSNEWGUIDANCE/en/>.

${ }^{20}$ La Vanguardia, 15 de enero de 2004, p. $31<\mathrm{http}$ //hemeroteca.lavanguardia.com/preview/2005/05/23/pagina31/33640927/pdf.html?search=gripe\%20del\%20pollo $>$.

${ }^{21}$ El 10 de junio de 2010, la OMS publicó una carta para responder a esas críticas <https://www.who.int/csr/disease/swineflu/notes/briefing_20100610/es/>.

${ }^{22}$ Algunos expertos han señalado que este episodio de 2009-2010 ha podido influir en la respuesta inicial bastante retraída de la propia OMS y de algunos Estados frente al SARS-CoV-2. No encender la alarma antes de tiempo seguramente evitó el alarmismo, pero no favoreció la lucha contra el coronavirus.

$23<$ https://www.who.int/emergencies/mers-cov/en/>.
} 
del "nuevo coronavirus de Wuhan, ciudad del centro de China donde se originó el brote"24. Se informaba que el virus había infectado a casi doscientas personas, causado tres muertes y detectado en China, Tailandia, Japón y Corea del Sur. La OMS tuvo conocimiento del patógeno causante de esta nueva forma de neumonía el 31 de diciembre de 2019. Desde esta fecha hasta el 3 de enero de 2020, las autoridades chinas registraron un total de 44 casos de la enfermedad, comunicados a la Organización Mundial de la Salud. El 7 de enero las autoridades sanitarias chinas identificaron el nuevo tipo de coronavirus, y desde el día 12 otros países empezaron a compartir la secuencia genética del nuevo patógeno. Después, todo fue muy rápido. En pocos días, China cerró la ciudad de Wuhan para frenar la expansión del virus; se impuso una cuarentena en esta ciudad, con millones de personas confinadas; el 25 de enero el virus ya estaba en Europa; y el 31, la OMS declaró la alerta internacional. El 1 de febrero el número de afectados en China se acercaba a los diez mil, y ya había una veintena de países con casos, entre ellos España, con un paciente de nacionalidad alemana, aislado en la isla canaria de La Gomera. El 20 de febrero, la OMS informaba que en China había 74.675 casos, con 2.121 fallecidos. Fuera de ese país, los casos registrados eran 1.073. Pocos días más tarde, el 6 de marzo los contagios en el mundo ya eran más de cien mil, los muertos se acercaban a los cuatro mil y los países afectados eran ya un centenar. El 11 de marzo la Organización Mundial de la Salud declaró pandemia a la COVID-19. La secuencia se puede seguir día a día, hasta hoy, en los informes que la OMS emite regularmente ${ }^{25}$.

En el recuerdo histórico quedan las pandemias de gripe de 1918-1919 (H1N1), la llamada gripe española, que causó alrededor de 50 millones de muertes ${ }^{26}$, la llamada gripe asiática (H2N2), causante de dos millones de muertes en 1957, y la llamada gripe de Hong Kong de 1968 (H3N2), causante de un millón de muertes en todo el mundo. En estos momentos, no deberían ser olvidadas tampoco las otras enfermedades infectocontagiosas activas a día de hoy: son alrededor de un millar que provocan millones de muertes al año o dejan a determinadas comunidades incapacitadas para generar sus recursos económicos, lo que causa falta de oportunidades sanitarias, educativas, habitacionales, entre muchas otras. Los datos actualizados de buena parte de estas patologías se pueden localizar fácilmente en las páginas web de la Organización Mundial de la Salud.

\section{El abandono de la salud pública internacional}

Hablando de esa organización, la OMS, hay que denunciar a los países más ricos por el abandono, cuando no la instrumentalización, desde hace varias décadas, de las instituciones comunes universales, como la $\mathrm{ONU}^{27}$, la OMS, la FAO o la $\mathrm{UNESCO}^{28}$, disminuyendo sus recursos o quitándoles su contenido sobre gobernanza global, salud, alimentación o educación. A las quejas de las mismas instituciones, como ya hemos señalado en este texto, se sumaron, desde hace tiempo, las de voces autorizadas que denunciaron el retroceso "sobrecogedor" de

\footnotetext{
${ }^{24}$ El País, 21 de enero de 2020, p. 26

<https://elpais.com/sociedad/2020/01/20/actualidad/1579494586_763520.html>.

25 El último informe consultado para este trabajo, el del 23 de abril de 2020, registraba un total de 2.544 .792 de casos confirmados por coronavirus y 175.694 muertes en todo el mundo < https://www.who.int/docs/defaultsource/coronaviruse/situation-reports/20200423-sitrep-94-covid-19.pdf?sfvrsn=b8304bf0_4>.

${ }^{26}$ Véase el interesante sitio web, inspirado por el demógrafo del CSIC, Diego Ramiro, comparativo entre la gripe rusa de 1889-1890 y la llamada gripe española de 1918-1920 <https://aulaesri.maps.arcgis.com/apps/Cascade/index.html?appid=c85a0f713e934a7abb83bad0d932e377>.

${ }^{27}$ La Organización de Naciones Unidas, en lucha contra el coronavirus <https://www.un.org/es/coronavirus>.

${ }^{28}$ La UNESCO, implicada en los problemas que está acarreando la pandemia del coronavirus en la educación $<$ https://es.unesco.org/>.
} 
los sistemas asistenciales y de salud pública occidentales desde mediados de la década de 1970 . Estas palabras de José María López Piñero, maestro de la historia de la medicina, fueron pronunciadas hace veinte años ${ }^{29}$. No se referían a España, que había sufrido una transformación positiva de sus instituciones sanitarias por aquellos años al dejar atrás la dictadura franquista. El mismo López Piñero afirmaba también que la desigualdad humana ante la enfermedad y el dolor era la más odiosa de todas; para combatir esa desigualdad se había creado el estado del bienestar, la gran conquista moral del siglo XX, eran sus palabras, una conquista a la que no han accedido, avanzado el siglo XXI, la mayor parte de las regiones del mundo.

El inicio de la demolición del estado del bienestar comenzó a finales de la década de 1970, tal como han denunciado algunos historiadores y científicos sociales. El pistoletazo de salida de aquella fue la crisis del petróleo de 1973-1975. Eric Hobsbawm apuntó al ascenso del thatcherismo como el acontecimiento inicial de ese proceso. La última "gran divergencia" ${ }^{30} \mathrm{de}$ clases sociales se inició en Gran Bretaña, con Margaret Thatcher como jefa de gobierno, y en Estados Unidos, con el presidente republicano Ronald Reagan, para extenderse más tarde por Europa. Para el historiador Josep Fontana, las consecuencias en esa "gigantesca redistribución de la riqueza no solo se manifestaron en el empobrecimiento relativo de los trabajadores e incluso de las clases medias, sino que otorgaron a las empresas una influencia política con la que (...) les resultó más fácil fijar las reglas que permitirían consolidar el proceso"31. Si el periodo de 1945 a 1975 había sido en el conjunto de los países desarrollados una etapa en la que un reparto más equitativo de los ingresos había permitido mejorar la suerte de la mayoría, la tendencia se truncó al final de ese período. En los Estados Unidos, por ejemplo, el 1 por ciento de los más ricos, que percibían en 1980 un 9 por ciento del ingreso total de la riqueza, habían aumentado en 2007 hasta el 23,5 por ciento de la misma. Los efectos de la divergencia de clases han sido idénticos en otras regiones del planeta, agudizados con la crisis económica que vino después, a pesar de las consignas de algunos voceros que anunciaban la refundación del capitalismo allá por los años 2008-2009. El pensador norteamericano Noam Chomsky reflexionaba años antes sobre ese modelo capitalista, afirmando que en realidad no era ni siquiera capitalista, sino un sistema económico en el que el sector público asumía colectivamente los costes y los riesgos, y el sector privado quedaba en manos de instituciones totalitarias $^{32}$. Si este modelo neoliberal depredador denunciado por Chomsky, Fontana, Amartya Sen, Naomi Klein, Thomas Piketty, o los premios Nobel Krugman y Stiglitz, entre otros, con sus muchos matices entre ellos, no es corregido, acabará por consolidar, a largo plazo, alguna de las peores distopías imaginadas en la ficción literaria o cinematográfica. El siglo XX ya padeció aproximaciones a las mismas. En demasiadas ocasiones, las crisis económicas, las guerras o los conflictos han servido para agrandar las divergencias de clase. El ejemplo de la última crisis económica global en los inicios del siglo XXI nos lo confirma. Quizás sea el tiempo de revertir esa tendencia.

Es el momento de pensar en el largo plazo y plantear un amplio programa científico interdisciplinar que se apoye en la epidemiología y en la salud pública, pero también en la

\footnotetext{
${ }^{29}$ El País, Babelia, 29 abril 2000, p. 15. La importancia de José María López Piñero para los estudios sobre la salud pública en España, en Jori, 25 de noviembre de 2010 <http://www.ub.es/geocrit/sn/sn-343-12.htm>.

${ }^{30} \mathrm{La}$ Gran Divergencia se ha usado conceptualmente de varias maneras y en diferentes escalas de tiempo. Una de las interpretaciones económicas en Casanova, 21 de noviembre de 2019 <https://dx.doi.org/10.7770/07192789.2019.cuhso.03.a03>.

${ }^{31}$ Fontana, 2011, p. 568.

32 Chomsky, 2003, p. 46.
} 
historia, la geografía ${ }^{33}$, la economía, la biología, la ecología, la antropología o la psicología, con el objetivo primero de plantar cara a los negacionismos más burdos: a los dirigentes políticos demagogos que hablan de un simple resfriado al referirse a la COVID-19, que priorizan la marcha de la economía, en realidad los intereses de algunos, por encima de la vida de las personas, y también a los que ven en la pandemia una conspiración de unos cuantos para quedarse con la riqueza de todos. Es difícilmente imaginable que casi todo el mundo esté equivocado, desde la Organización Mundial de la Salud hasta los servicios epidemiológicos más destacados del planeta, $y$, en cambio, estén en posesión de la verdad los que no saben nada de epidemias ni de salud pública, o los que ven conspiraciones militares, económicas o políticas por todos los lados. En el mismo sentido, otro capítulo del ya referido Prontuario de Mencken lo escribe el presidente de Estados Unidos de América, Donald Trump, cuando acusa a la OMS de sinocentrismo, es decir, de favorecer los intereses chinos, una pirueta para suspender los fondos que aporta EEUU a la organización internacional de la salud y, de paso, esconder una mala gestión de la salud pública en ese país. Algún apartado del mismo capítulo lo protagoniza el presidente de Brasil, Jair Bolsonaro, al saltarse las recomendaciones epidemiológicas básicas, entre ellas la de no promover aglomeraciones de personas. El llamado distanciamiento social está siendo señalado por los científicos como una de las armas más eficaces para luchar contra esta enfermedad extremadamente infectocontagiosa.

\section{Las epidemias no se fueron nunca}

En ningún caso, esta grave crisis epidemiológica debe simplificarse diciendo que la causa de la misma es debida al contagio primigenio entre animales domésticos enjaulados, como el pangolín, o de murciélagos que han perdido su hábitat natural, y de los seres humanos en Wuhan, en la provincia china de Hubei. Aunque así sea en el primer eslabón de la cadena, lo cual es muy plausible, las reflexiones finales deben ir más allá. No se debe esperar a la siguiente calamidad natural, sea una pandemia vírica, una plaga animal, o el calentamiento global del planeta, otro tabú negacionista, para empezar a pensar y actuar decididamente. No es baladí recordar que si bien el conocimiento científico de las epidemias y plagas de todo tipo tiene poco más de cien años -pensemos en las teorías miasmáticas de algunas enfermedades o en las confusas ideas de las plagas en general como castigo divino hasta fechas recientes-, uno de los agentes causantes de epidemias, las bacterias, llevan 3.000 millones de años sobre la Tierra, el tiempo que les sirvió para adaptarse a algunas de sus cepas a su futura existencia parasitaria en la que aprendieron a nutrirse de otras criaturas. Se ha señalado también, desde hace tiempo, el papel beneficioso de muchas bacterias, y nuestra interacción con ellas puede dirigir la evolución de las mismas. Debido al abuso de los antibióticos y a una asepsia excesiva, se produce una selección de las cepas más patógenas. Es el caso de las bacterias hospitalarias multirresistentes.

Similares observaciones pueden hacerse sobre los virus y otros elementos patógenos para el género humano. Los distintos causantes de patologías emergen con viejas y nuevas formas, y en algunos casos causan epidemias. Del dinamismo de los microorganismos nos da nuevas el naturalista Edward O. Wilson. Los que denomina "superbichos" nos deben hacer reflexionar. Wilson ha señalado que la bacteria Pyrolobus fumarii puede reproducirse a $113^{\circ} \mathrm{C}$, o que otra, la Deinococcus radiodurans, puede vivir "en medio de radiación tan intensa que el cristal de

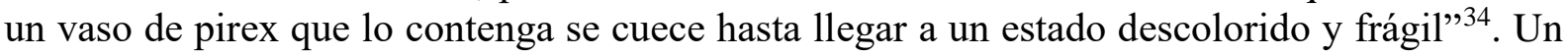

\footnotetext{
${ }^{33}$ Véase el web de la Asociación Española de Geografía (AGE), que promueve el intercambio de textos y reflexiones sobre la pandemia del coronavirus <https://www.age-geografia.es/site/reflexiones-sobre-la-crisisactual/>.

${ }^{34}$ Wilson, 2002, p. 33.
} 
ser humano expuesto a la energía de mil rads, o sea, la dosis que emitieron las explosiones de Hiroshima y Nagasaki, continúa Wilson, muere pasadas una o dos semanas. A un millón de rads, el crecimiento del Deinococcus se hace más lento, pero todas las bacterias sobreviven. El secreto de este superbicho es su extraordinaria capacidad para reparar ADN roto. Los virus son asimismo muy dinámicos; sufren mutaciones y recombinaciones, transformando su código genético con gran rapidez.

Frente a ese dinamismo, la respuesta humana, desde el punto de vista biológico, es lenta, pues se realiza a través de la selección natural en cada generación, que cambia nuestras frecuencias génicas. Los microbios, las bacterias y los virus, sin embargo, en medios favorables, pueden reproducirse en horas o minutos, quedando seleccionados aquellos más adaptados al medio. Desde hace tiempo se habla de la historia evolutiva de las especies como una historia de acoplamiento estructural y de coevolución, es decir, de un proceso resultante de la evolución de los organismos vivos con su entorno ${ }^{35}$. El hombre se ha convertido en un transformador del medio físico y no se puede prever las consecuencias de dicha intervención. En lo que se ha definido como "mercado común microbiano" 36 , hay que contar con la imposibilidad de erradicar los reservorios de plagas, a pesar del éxito logrado con la viruela. La evolución es inevitable y con ella pueden aparecer nuevos patógenos. Nadie discute ya que el hombre, especialmente desde lo que se conoce como revolución industrial, se ha convertido en el agente con más responsabilidades frente a la naturaleza, al transformar las condiciones de existencia de los microorganismos y provocar su desestabilización ${ }^{37}$. Pensemos en la penetración del hombre en territorios anteriormente despoblados, alterando los ecosistemas existentes. La extraordinaria obra del geógrafo Clarence J. Glacken estableció de manera precisa esas relaciones entre naturaleza y sociedad, y de manera especial las del hombre como agente modificador de la naturaleza ${ }^{38}$.

Las plagas y epidemias no conocen fronteras ${ }^{39}$. No las conocieron a lo largo de la historia. Eurasia y África estuvieron permanentemente en contacto, y así participaron en ese mercado común microbiano. De Asia vino a Europa la peste en el siglo XIV. En India se originó el cólera que castigó duramente a Europa en el siglo XIX. La viruela, el sarampión o la gripe mataron a cientos de millones de individuos a lo largo de los siglos en los tres continentes. América sufrió con dureza su aislamiento, a partir de lo que se conoce como intercambio colombino. Sus poblaciones fueron diezmadas gravemente por el contagio con los patógenos que llevaron los europeos. Todo ese intercambio ya no colombino, sino fruto de la revolución industrial, se ha acelerado en los dos últimos siglos, y de manera exponencial en los últimos treinta años. El orden político y económico del siglo XX se deshizo con la caída de la URSS. En 2020 hay claramente otros actores principales. El término globalización ha pasado a ser de uso común en todo el planeta. Su fenomenología ha de ser analizada como un proceso imparable. A las inmensas posibilidades que ha traído la globalización, hay que añadir el hecho de que se ha

\footnotetext{
${ }^{35}$ Margalef, 1992, p. 252.

36 McNeill y McNeill, 2003, p. 199.

${ }^{37}$ Mary E. Wilson, 23 de diciembre de 1995, p. 1.681-1.684 <https://www.ippnw.org/pdf/mgs/3-wilson.pdf>. También, las reflexiones en la misma línea de Dorothy H. Crawford, 2002, p. 62-63.

${ }^{38}$ Glacken, 1996.

${ }^{39}$ Aunque los efectos de plagas y epidemias son notablemente distintos en una sociedad u otra, con sistemas de protección diferenciados, la sociedad global de hoy no puede impedir que millones de personas, turistas, estudiantes, trabajadores, migrantes, pero también animales o elementos patógenos, y por supuesto mercancías, sufran y gocen de un trasiego permanente. El riesgo cero no existe en ningún caso. Las fronteras se pueden cerrar temporalmente, se pueden levantar muros, pero el mundo cerrado, eremita, si existió alguna vez, está perdido para siempre.
} 
convertido objetivamente en una promotora implícita de epidemias y plagas. Hay muchos ejemplos que nos han afectado directamente en los últimos tiempos. El mosquito tigre (Aedes albopictus), originario del sudeste asiático, se ha expandido en pocos años en buena parte de la península Ibérica. En algunos lugares del mundo hace de vector de algunas patologías infectocontagiosas graves. Las especies invasoras en España son numerosas. El fenómeno es universal, y en sí no tiene por qué ser exclusivamente negativo. El mencionado intercambio colombino posibilitó que plantas y animales fueran trasladados de unos continentes a otros. La alimentación humana mejoró enormemente. La última globalización ha universalizado de manera exponencial el intercambio de individuos, de animales, de mercancías y también de elementos patógenos.

El turismo de masas lleva a centenares de millones de personas de unos continentes a otros. Los datos sobre el turismo internacional impresionan. En 2017 los turistas internacionales se contabilizaron en 1.326 millones. Ese mismo año, la actividad económica en torno al turismo generó el 10 por ciento del PIB en la Unión Europea ${ }^{40}$. Hace dos años, mi hijo hizo las prácticas universitarias en Seúl. Su madre decidió que la familia debía pasar junta las vacaciones de verano. Después de un viaje de algo más de quince horas de avión, los padres se plantaron en Corea del Sur. Tres semanas en ese país, con un vuelo interior de avión, un viaje en barco, otro en ferrocarril y un automóvil alquilado. Una experiencia personalmente muy enriquecedora: el descubrimiento de Oriente. El libro de cabecera de ese viaje fue La descripción del mundo, de Marco Polo. El capítulo VIII de este libro de maravillas apunta que el viaje de micer Nicoló, micer Mateo y Marco hasta Chemeinfú (Kai-ping-fu, al norte de la Gran Muralla y del río Luan, en Mongolia, a 700 "li" (leguas) de Pekín, en nota a pie de página de la edición de J.L. Borges) "les costó tres años, debido al mal tiempo y a los ríos, que estaban crecidos lo mismo en invierno que en verano, de tal guisa que no pudieron cabalgar" ${ }^{41}$. Tres años para llegar desde Venecia a Mongolia. El abuelo materno del que esto escribe nació en un pequeño pueblo en Teruel e hizo el servicio militar de tres años en Girona. No volvió en todo ese tiempo al pueblo. La novia que tenía se casó con otro hombre, y mi abuelo se casó con mi abuela, que solo se desplazó de su pueblo por la guerra civil. Al final de su vida, mi abuela pasaba los inviernos en Barcelona, al convivir con la familia de su hija, mi madre. Microhistorias que explican algunas de las cosas importantes que han pasado en el último siglo, cuatro generaciones, Marco Polo aparte. Si sabemos que el turismo de masas genera intercambio microbiano ${ }^{42}$, como no puede ser de otra manera, también los desplazamientos forzosos, como las migraciones políticas o económicas, tienen los mismos efectos. De manera especial cuando ha habido conflictos armados. En el mundo hay millones de personas en campos de refugiados.

\section{¿Se aprenderá de esta novedosa vieja pandemia?}

Frente al concepto engañoso de erradicación de plagas y epidemias, quizás sea más útil primero intentar prevenirlas, y después, si surgen, pensar en su control, pues incluso su aparente desaparición no es garantía de que se hayan ido para siempre. Ese control debe ser asumido, a día de hoy, por los Estados, en compañía de los organismos internacionales de la salud. Estos no tienen poder ejecutivo a día de hoy, pero sí pueden prestar, si están bien dotados de medios científico-técnicos y de mayor capacidad para intervenir, información para combatir las

\footnotetext{
${ }^{40}$ Zaar, 1 de febrero de 2019 <http://www.ub.edu/geocrit/aracne/aracne-230.pdf >.

${ }^{41}$ Polo, 1987, p. 22.

${ }^{42}$ Mary E. Wilson, 1995, p. 39-46 <https://dx.doi.org/10.3201/eid0102.950201>.
} 
pandemias. Los Estados deben de estar al servicio de toda la población, con políticas democráticas y transparentes. Es necesario reconquistar de nuevo el concepto de estado de bienestar, y ampliarlo al mayor número de países.

En momentos excepcionales como el actual, hay que recuperar el discurso ilustrado. Es el momento de las ciencias aplicadas para combatir las pandemias, y hay que agradecérselo a los científicos, a los sanitarios, y a todos los que hacen posible la lucha contra la enfermedad, en estos momentos contra la COVID-19, pero igual de importante son a corto y a medio plazo las Ciencias Humanas. Hay que pensar en el interés colectivo, y la mejor manera de defenderlo es poner en marcha políticas públicas fuertes. El saber -humanístico, decimos nosotros- constituye por sí mismo un obstáculo contra el delirio de omnipotencia del dinero y el utilitarismo, escribía Nuccio Ordine, en un libro con un título llamativo, pero certero: La utilidad de lo inútil. Manifiesto (Barcelona, 2013). Esa omnipotencia que acaba arrasando con los bienes comunes, sean bosques, el aire y el agua de todos, o los recursos naturales de todo tipo, que solo benefician a unos pocos y empobrecen a muchos. Con diferentes palabras a las de Ordine, pero igual de sabias, en una entrevista reciente en televisión al expresidente de Uruguay, Pepe Mújica, este se preguntaba para qué carajo querían acumular plata los viejos multimillonarios, si se iban a morir igual que los demás. Su sonrisa irónica transmitía la dignitas cum auctoritate, la de la sabiduría del Marco Aurelio meditativo.

Se pueden aprovechar las inercias positivas generadas en estos meses en buena parte del planeta. La más importante: solo nos podemos salvar juntos de la pandemia. De este mensaje solidario, somos testigos directos a pesar de las situaciones de confinamiento. Los actuales medios de comunicación son ventanas abiertas a todo el mundo. Nosotros vemos; los otros nos ven. En pocos días de confinamiento, aplicado en casi todo el planeta, hemos visto cómo se han puesto en marcha numerosas iniciativas positivas; por ejemplo, en general se ha reconocido que la humanidad está en guerra contra un enemigo común, el coronavirus, que solo juntos se puede vencer a ese enemigo, o que el confinamiento colectivo es necesario para no infectar a los demás. Muchas personas, desde gente anónima a profesionales de todo tipo, han llevado la solidaridad a la gente más necesitada. Los medios de comunicación de todo el mundo llevan mensajes idénticos, lo podemos seguir por los canales de televisión o a través de internet. Las reacciones emocionales frente al problema se han copiado a lo largo del planeta, y se han transmitido mensajes optimistas: la humanidad está en la misma barca, es una. Hace poco más de cien años, y somos cautos, este mensaje era difícil de encontrar. Lo hacían suyo los anarquistas, los socialistas y los liberales más avanzados. La mitad de la población, las mujeres, no eran consideradas sujetos políticos en la mayoría de los países del mundo. El racismo más burdo campaba a sus anchas. El catálogo de obras publicadas, incluso por catedráticos de universidad, de marcado carácter racista, era amplio. Normalmente estaba asociado a las ambiciones imperialistas europeas.

Por supuesto, también han aparecido muchas espinas con la pandemia actual. Ya se han denunciado algunas. La más dolorosa es el daño causado a las personas, las muertes, los hospitalizados, el trabajo agotador del personal sanitario y no sanitario, el miedo e incertidumbre de la población, las empresas y el trabajo que están en el aire, un futuro con muchos interrogantes, seguramente tantos como personas. En el plano colectivo, muchos gobiernos han tomado decisiones poco acertadas ante la pandemia, claramente por desconocimiento científico ante un mal muy nuevo; ha aparecido la insolidaridad y la competencia entre países por el abastecimiento de material sanitario; hemos podido comprobar el papel errático de la Unión Europea, su casi desaparición en esta crisis, lo que puede poner en 
riesgo su misma existencia; la xenofobia de algunos grupos políticos contra los inmigrantes en momentos tan delicados; o el comprobar la poca talla moral de algún jefe de gobierno. Alguno ha planteado políticas cercanas a la eugenesia encubierta, otros han negado el problema pandémico o han frivolizado sobre los cientos de miles de muertos que puede generar la pandemia en su país.

Europa tiene en estos momentos una oportunidad magnífica para aprender de su propia historia, contemplándose particularmente en el espejo alemán. Cabe salir de esta crisis de manera desunida, con culpas, rescates, castigos y sanciones imposibles de pagar, como ocurrió después de la Primera Guerra Mundial para Alemania, provocando el derrumbe de la avanzada República de Weimar y el auge del nazismo. O con compromisos entre los ganadores y perdedores, después de la Segunda. La primera vio nacer a algunos de los peores monstruos de la historia; la segunda sirvió para generar pactos que llevaron a la consolidación del modelo con más éxito colectivo nunca conseguido en la historia de la humanidad: el llamado estado del bienestar. En su puesta en marcha influyó, sin duda, el miedo a la revolución comunista. Otro ejemplo histórico más reciente, aunque menos dramático, fue la salida a la crisis financiera de 2008 en Europa. Se pusieron en marcha políticas de gran austeridad fiscal. Esta provocó graves crisis sociales en varios países de la Unión Europea. Sus efectos se siguen notando todavía hoy. Los signos de desunión aparente en la Europa actual frente al coronavirus, y un casi sálvese quien pueda en los primeros momentos de la pandemia, no presagian, de momento, lo mejor. Afloran seguramente los intereses de los más poderosos y la xenofobia latente de algunos de sus servidores. Si no se produce ese nuevo pacto histórico dentro de la Unión Europea, que ayude a los países más castigados por la enfermedad, será imposible que arraigue compromiso alguno de ayudar a los más vulnerables en otros lugares del mundo. Muchos europeos se preguntarán asimismo para qué sirve la UE, si cuando más se necesita desaparece del mapa. Las políticas antieuropeas y populistas pueden estar servidas. De la misma manera, Europa deberá prestar especial atención a los países menos desarrollados.

Deberán pasar algunos meses, quizás años, para comprender el alcance global de la crisis sanitaria de la COVID-19 de 2020 y las responsabilidades de la misma. No solo el alcance epidemiológico, averiguando las características del virus, sus transmisores, su modelo de difusión, las maneras de combatirlo, los modelos de medicina y hospitales que se necesitan. De manera especial, habrá que averiguar qué modelos de salud pública se pueden y quieren poner en marcha. También, saber las consecuencias económicas de la pandemia, cómo y quienes pagarán la factura de unas economías paralizadas prácticamente en todo el mundo, cómo ha respondido eso que genéricamente se conoce como mercado, o quizás, a lo mejor esta calamidad sirva para poner en cuestión el modelo actual de consumo obsceno por parte de una minoría y la pobreza extrema de muchos. Es posible que, a partir de ahora, valoremos más los productos de cercanía de nuestros agricultores, y encontremos absurdo consumir artículos traídos en avión para nuestras mesas. Tal vez sirva para revisar las relaciones industriales en el planeta, y relocalizar industrias esenciales -incluidos medicamentos o material sanitario- en aquellos países que las habían localizado en otros con costes más baratos, de manera especial en lo que se ha conocido como la fábrica del mundo, China. El zoco vergonzoso entre Estados, gobiernos nacionales y gobiernos regionales, en el que se convirtió el mercado de los productos sanitarios en los momentos críticos de la pandemia, no solo en España, debe de hacer recapacitar a los responsables políticos. También será interesante averiguar las implicaciones ecológicas de esta crisis: los mapas de Europa de contaminación de estos días han variado sustancialmente, como consecuencia de la ralentización del consumo de energías fósiles. A lo mejor, lo que ha pasado pone en marcha definitivamente políticas que privilegien la movilidad pública sobre el transporte privado. Todo esto hay que educarlo. El futuro se decidirá en la educación. Esta debe 
ser pública y de calidad. A diferencia de ciertas máquinas, o sea de los ordenadores, vendidos estos días de confinamiento como panacea para casi todo, para el trabajo, las compras, el control de las emociones, el entretenimiento, y también para la enseñanza, hay que reivindicar la figura de la escuela, del maestro, capaz de despertar, en palabras de George Steiner, "poderes, sueños que están más allá de los nuestros; inducir en otros el amor por lo que nosotros amamos; hacer de nuestro presente interior el futuro de ellos ..."43. Esa capacidad para asombrar y asombrarse con emociones y empatía hacia los otros solo se puede dar entre personas.

La pandemia por coronavirus también puede remover la política, que sirva para reafirmar o no el papel de los Estados, y que ayude a discernir los sistemas con más resiliencia ante esta calamidad. A escala supranacional, habrá que pulsar el papel de la Unión Europea en esta crisis, ya se ha dicho, o el papel de las fronteras entre los países; a nivel planetario, habrá que analizar cómo se configura el nuevo mapa geopolítico mundial. El trabajo a realizar se ha de hacer desde distintas escalas. También valdrá la pena saber de los procesos sociológicos, antropológicos y psicológicos surgidos, que se analice cómo reaccionaron ante la adversidad los individuos o los grupos humanos, de qué manera se respetaron las normas emitidas por las autoridades, o, un doloroso ejemplo, cómo vivieron el duelo las decenas de miles de personas que no pudieron enterrar en ceremonia ni acompañar en los últimos momentos a sus seres queridos. Hay que hacerse preguntas. Habrá que estudiar muchos otros aspectos, como los relacionados con el papel de la tecnología en esta crisis, el de los medios de comunicación, de la educación, de la seguridad colectiva, del papel de los ejércitos, de los agricultores y ganaderos, parias de esta sociedad hiperconsumista, de los modelos de transportes o el diseño de las ciudades. Muchas cosas deberán ser revisadas. Si Barcelona necesitó un Ildefonso Cerdá para crear un nuevo urbanismo, que higienizó y amenguó los males provocados por el cólera en el siglo XIX, hoy se necesitan unos cuantos pensadores que rediseñen las nuevas urbes no sólo contra las contingencias de los virus, sino para crear los nuevos marcos de convivencia que aparezcan. En estos tres meses pasados, casi acabado ya el mes de abril, el mundo ha sido un laboratorio. Los científicos sociales están emplazados a hacer un buen diagnóstico para prevenir nuevos embates, no solo de los virus.

\section{A modo de conclusión}

Creemos sobradamente haber demostrado que las viejas y las nuevas epidemias en realidad son viejas y nuevas al mismo tiempo. No se han ido, ni se van a ir. El género humano va a tener que convivir, como ha convivido hasta ahora, nos lo enseña la historia, como un elemento más de la naturaleza, entre bacterias, virus y patógenos cambiantes. Según en qué parte del planeta habite, o según se modifique esa naturaleza, se enfrentará a unos u otros de esos enemigos, nos lo enseña la geografía y la ecología. La organización social, política y económica de los Estados se vio afectadas en el pasado por las calamidades naturales, entre ellas las pandemias, ocurre hoy, y ocurrirá en el futuro, como explicó Eric L. Jones, que analizó los factores diferenciales que posibilitaron lo que se conoce como milagro europeo. Esos factores permitieron que el entorno natural de Europa, favorable respecto al de Asia, junto a la labor de cercenamiento del poder arbitrario, alentaran la inversión y promovieran el crecimiento de aquella parte del planeta. La revolución industrial vino a confirmar el dominio mundial de Europa y las llamadas nuevas europas sobre el resto del planeta hasta fechas recientes. El mundo ha cambiado sustancialmente en poco tiempo. La última globalización lo ha trastocado todo. Emulando a

\footnotetext{
${ }^{43}$ Steiner, 2016, p. 173.
} 
E.L. Jones, creemos que hoy se necesita un milagro de escala planetaria. Este milagro necesita otro milagro: las tensiones que sobrevengan deben dirimirse de manera pacífica. Hay que darle contenido real a las Naciones Unidas.

Otra de las consecuencias imprevisibles de esta crisis es una constatación simple: el capitalismo deberá ser redefinido. Si algo ha demostrado esta crisis de 2020 es que se puede desvanecer en el aire, en la célebre expresión de Marx. Cuando se hundieron la URSS y sus satélites, algunos voceros anunciaron el fin de la historia. En realidad, solo nos querían decir que había que aceptar las propuestas de las clases dominantes, que no había alternativas. Pero, los sistemas sociales, más que ninguno el capitalismo, transitan muy rápido, son tremendamente inestables y son poco sólidos, lo estamos comprobando estos días, para reclamar una estabilidad prolongada. El sistema que llamamos capitalista está permanentemente transformándose, desintegrándose, recomponiéndose, cambiando. Algunos de los mayores logros de la humanidad se han conseguido en esta etapa histórica. También algunas de las mayores atrocidades hay que cargarlas en su haber. La manera como se recomponga de esta crisis implicará más democracia, con más equidad económica, política, sanitaria o educacional, por poner algunos ejemplos, ayudando a sostener o promover estados de bienestar, o bien, en sentido contrario, el denunciado por Noam Chomsky. O, quizás, habrá que reemplazarlo por inservible. En el título de este trabajo se dice también que esta pandemia no es la Tercera Guerra Mundial. Tal como hemos conocido las guerras, no, pero quizás las guerras ya no tienen por qué desarrollarse al modo clásico, ni siquiera con aviones ni drones. Habrá que estar atentos. En ese proceso de reconfiguración del mundo al que estamos asistiendo es extraordinariamente sugerente la obra de Peter Frankopan, titulada The Silk Roads: el centro de gravedad del mundo está cambiando, regresando a donde estuvo durante milenios. De esto hemos sido testigos en tan apenas veinte años, lo que lleva andado este siglo. Que el virus que ha puesto en jaque todo el entramado mundial, no solo económico, venga de China parece algo más que una ironía. Sí, el siglo XXI va a tener muchos años interesantes.

\section{Agradecimientos}

Varios amigos y amigas leyeron el texto e hicieron sugerencias siempre inteligentes. Les doy las gracias. Los posibles fallos, son solo míos. Lo escribí a finales de marzo y parte de abril de 2020, durante el confinamiento por el SARS-CoV-2. Ninguno de nosotros imaginó nunca que viviría una situación semejante. Muchos días, mi familia vivió la angustia de tener a nuestro amigo Leoncio en un hospital de Madrid, atacado por el coronavirus. En nuestras vidas habrá un antes y un después por todo lo vivido durante estos días. Francisca Guerola me ayudó a comprender mejor algunos conceptos de biología. A Horacio Capel le doy una vez más las gracias por su confianza.

\section{Bibliografía}

BUJ BUJ, Antonio. Los riesgos epidémicos actuales desde una perspectiva geográfica. Scripta Nova. Revista Electrónica de Geografía y Ciencias Sociales. [En línea]. Barcelona: Universitat de Barcelona. 1 de mayo de 1999, no 39 <http://www.ub.edu/geocrit/sn-39.htm>.

BUJ BUJ, Antonio. Los riesgos epidémicos desde una perspectiva geográfica. Papeles de Población. [En línea]. Toluca: UAEM, julio-septiembre 2001, $\mathrm{n}^{\circ} \quad 29$, 193-223 $<$ http://www.scielo.org.mx/pdf/pp/v7n29/v7n29a10.pdf >.

BUJ BUJ, Antonio. El viejo problema de las nuevas plagas. Una mirada histórico-geográfica a los riesgos epidémicos en los inicios del siglo XXI. Treballs de la Societat Catalana de 
La COVID-19 y las viejas epidemias. No es la tercera Guerra Mundial, es el capitalismo

Geografia. [En línea]. Barcelona: Societat Catalana de Geografia. 2003, no 55, 21-56 <https://www.raco.cat/index.php/TreballsSCGeografia/article/view/10445/261541>.

BUJ BUJ, Antonio. Plagas de langosta. De la plaga bíblica a la ciencia de la acridología. Barcelona: Ediciones del Serbal, 2016.

BURNET, Sir Macfarlane y WHITE, David O. Historia natural de la enfermedad infecciosa. Madrid: Alianza Universidad, 1982 (ed. inglesa, 1972).

CASANOVA, Mauricio. En torno a los orígenes de la Gran Divergencia: debates recientes en historia económica (2000-2018). Cultura-hombre-sociedad. [En Línea]. Temuco: Universidad Católica de Temuco, 21 de noviembre de 2019 <https://dx.doi.org/10.7770/07192789.2019.cuhso.03.a03>.

CHOMSKY, Noam. Dues hores de lucidesa. Converses amb Denis Robert $i$ Weronica Zarachowicz. Barcelona: Edicions 62, 2003.

CRAWFORD, Dorothy H. El enemigo invisible. La historia secreta de los virus. Barcelona: Península, 2002 (ed. inglesa, 2000).

CROSBY, Alfred W. El intercambio transoceánico. Consecuencias biológicas y culturales a partir de 1492. México: Universidad Nacional Autónoma de México, 1991 (ed. inglesa, 1977).

DIAMOND, Jared. Armas, gérmenes y acero. Madrid: Editorial Debate, 1998.

FONTANA, Josep. Por el bien del imperio. Una historia del mundo desde 1945. Barcelona: Pasado \& Presente, 2011.

FRANKOPAN, Peter. El corazón del mundo. Una nueva historia universal. Barcelona: Crítica, 2016.

FRANKOPAN, Peter. The New Silk Roads. The present and future of the World. Londres: Bloomsbury Publishing, 2018.

GARRETT, Laurie. The coming plague: newly emerging diseaseas in a world out of balance. Nueva York: Penguin Books, 1995.

GLACKEN, Clarence J. Huellas en la playa de Rodas. Naturaleza y cultura en el pensamiento occidental desde la Antigüedad hasta finales del siglo XVIII. Barcelona: Ediciones del Serbal, 1996 (ed. inglesa de 1967).

GOULD, Peter y KABEL, Joseph. La epidemia de SIDA desde una perspectiva geográfica. Geo Crítica. [En línea]. Barcelona: Universidad de Barcelona, septiembre de 1990, $\mathrm{n}^{\circ} 89$ <http://www.ub.edu/geocrit/geo89.htm>.

HAGETT, Peter. Geographical aspects of the emergence of the infection diseases. Geografiska Annaler, 1994, no 76 B, p. 91-104.

JONES, E. L. El milagro europeo. Madrid: Alianza Universidad, 1990 (ed. inglesa de 1981). 
JORI, Gerard. José María López Piñero y la historia de la salud pública. Scripta Nova. Revista Electrónica de Geografía y Ciencias Sociales. [En línea]. Barcelona: Universidad de Barcelona, 25 de noviembre de 2010, vol. XIV, no 343 (12). < http://www.ub.edu/geocrit/sn/sn-343/sn343-12.htm>.

LÓPEZ PIÑERO, José María. La medicina en la Historia. Madrid: La Esfera de los Libros, 2002.

MARGALEF, Ramón. Planeta azul, planeta verde. Barcelona: Prensa Científica, 1992.

McNEILL, J. R. y McNEILL, W. H. Las redes humanas. Una historia global del mundo. Barcelona: Crítica, 2003.

McNEILL, William H. Plagas y pueblos. Madrid: Siglo XXI, 1984 (ed. inglesa, 1976).

OLDSTONE, Michael B. A. Viruses, plagues and history. Oxford: Oxford University Press, 2000.

POLO, Polo. La descripción del mundo. Barcelona: Orbis, 1987.

SALUZZO, Jean-François. Des hommes et des germes. París: Presses Universitaires de France, 2004.

ROSEN, George. A History of Public Health. Nueva York: MD Publications, Inc., 1958.

SIGERIST, Henry E. Civilización y enfermedad. México: Fondo de Cultura Económica, 1987 (ed. inglesa, 1943).

STEINER, George. Lecciones de los maestros. Madrid: Siruela, 2016.

VIANA SUPERVIOLA, Enrique; HILL, Katherine; ORIFE, Oghogho; FERRARIO, Chiara. Los condicionantes geográficos del ébola.Ar@cne. Revista Electrónica de Recursos de Internet sobre Geografía y Ciencias Sociales. [En línea]. Barcelona: Universidad de Barcelona, $\mathrm{n}^{\circ}$ 236, 1 de noviembre de 2019. <http://www.ub.edu/geocrit/aracne/aracne-236.pdf >.

WILSON, Edward O. El futuro de la vida. Barcelona: Galaxia Gutenberg/Círculo de Lectores, 2002.

WILSON, Mary E. Travel and the Emergence of Infectious Diseases. Emerg Infect Dis. 1 (2), p. 39-46, $1995<$ https://dx.doi.org/10.3201/eid0102.950201>.

WILSON, Mary E. Infectious diseases: an ecological perspective. British Medical Journal. Londres: British Medical Association, 311 (7021), p. 1.681-1.684, 23 diciembre de 1995 <https://www.ippnw.org/pdf/mgs/3-wilson.pdf>.

ZAAR, Miriam-Hermi. Gentrificación y turismo urbano. ¿Cómo se articulan? Ar@cne. Revista Electrónica de Recursos de Internet sobre Geografía y Ciencias Sociales. [En línea]. Barcelona: Universidad de Barcelona, $\mathrm{n}^{\mathrm{o}} 230,1$ de febrero de 2019. <http://www.ub.edu/geocrit/aracne/aracne-230.pdf >. 


\section{Páginas web}

Centers for Disease Control and Prevention <https://www.cdc.gov/coronavirus/2019ncov/index.html>.

Comisión Nacional de Salud de la República Popular China <http://www.nhc.gov.cn/xcs/yqtb/202003/c521093a01734df3b3fbc156064ba19f.shtml>.

El País <https://elpais.com/>.

Johns Hopkins University \& Medicine <https://coronavirus.jhu.edu/map.html>.

La Vanguardia <https://www.lavanguardia.com/>.

Ministerio de Sanidad, Consumo y Bienestar Social/España $<$ https://www.mscbs.gob.es/en/profesionales/saludPublica/ccayes/alertasActual/nCovChina/situacionActual.htm $>$.

Organización Mundial de la Salud <https://www.who.int/emergencies/diseases/novelcoronavirus-2019/situation-reports>.

Robert Koch Institut <https://www.rki.de/EN/Home/homepage_node.html>.

(C) Copyright: Antonio Buj Buj, 2020.

(c) Copyright: Ar@cne, 2020.

Ficha bibliográfica:

BUJ BUJ, Antonio. La COVID-19 y las viejas epidemias. No es la Tercera Guerra Mundial, es el capitalismo.Ar@cne.Revista Electrónica de Recursos de Internet sobre Geografía y Ciencias Sociales. Barcelona: Universidad de Barcelona, 1 de mayo de 2020, vol. XXIV, $\mathrm{n}^{\text {o }} 242$ <https://doi.org/10.1344/ara2020.242.31379>.

\section{Menú principal de Geo Crítica}

